\title{
The spot urine sodium-to-potassium ratio as a marker of hypertension risk
}

\author{
Yasuharu Tabara ${ }^{1,2}$ \\ Received: 15 January 2022 / Accepted: 24 January 2022 / Published online: 25 February 2022 \\ (c) The Author(s), under exclusive licence to The Japanese Society of Hypertension 2022
}

Excessive sodium intake has long been recognized as a risk factor for hypertension. The first step to preventing hypertension is to accurately calculate one's sodium intake. Because approximately $93 \%$ of dietary sodium is excreted in the urine [1], 24-h urine collections can be used to determine real-time sodium intake. However, due to the substantial day-to-day variation in dietary sodium intake, it is difficult to obtain an accurate estimate of the usual sodium intake from a single 24 -h urine collection. Therefore, repetitive sampling may be necessary to accurately estimate sodium intake [2], but it is inefficient and timeconsuming for primary prevention.

Recently, great emphasis has been given to the urinary sodium/potassium ratio $(\mathrm{Na} / \mathrm{K}$ ratio) as another indicator of the burden of sodium on blood pressure (BP). Because potassium lowers $\mathrm{BP}$, the $\mathrm{Na} / \mathrm{K}$ ratio is more closely correlated with concurrently measured BP than sodium alone or dietary sodium intake [3], as estimated by the Tanaka formula [4]. Furthermore, since the $\mathrm{Na} / \mathrm{K}$ ratio does not require a creatinine value, it can be easily determined with simple equipment [5] that enables the recording of several measurements over the course of a day. According to a previous study [6], measurements of six random daytime casual urine samples on separate days are necessary to determine the usual $\mathrm{Na} / \mathrm{K}$ level. However, it is unclear how many measurements are required to achieve $\mathrm{Na} / \mathrm{K}$ values that can be relied upon for assessing hypertension risk. According to a study published in this issue of Hypertension Research, Kogure et al. [7] reported the result of an association analysis between multiple daily measured

Yasuharu Tabara

tabara@s-sph.ac.jp

1 Graduate School of Public Health, Shizuoka Graduate University of Public Health, Aoi-ku, Shizuoka 420-0881, Japan

2 Center for Genomic Medicine, Kyoto University Graduate School of Medicine, Sakyo-ku, Kyoto 606-8507, Japan morning urinary $\mathrm{Na} / \mathrm{K}$ ratios and home $\mathrm{BP}$ levels that helped to resolve this unanswered question. From an analysis of the 1-day to 10-day mean values of the urinary $\mathrm{Na} /$ $\mathrm{K}$ ratios and home-measured BP levels, they suggested that a measuring period of more than three days would be beneficial. These valuable findings contribute to the practical application of the spot urine $\mathrm{Na} / \mathrm{K}$ ratio as a marker of hypertension risk.

Another issue that makes the practical application of the $\mathrm{Na} / \mathrm{K}$ ratio difficult is the lack of an exact cutoff value. Due to the linear correlation between the urinary $\mathrm{Na} / \mathrm{K}$ ratio and home BP level, Kogure et al. [6] were unable to determine a cutoff value using the same dataset. However, as shown in Table 2 of Kogure's publication, a urinary $\mathrm{Na} / \mathrm{K}$ ratio $\geq 6.0$ was consistently associated with the home BP level with an odds ratio greater than 2.0, regardless of the number of measurement days, and approximately $20 \%$ of the subjects in their study had a 10-day mean urinary $\mathrm{Na} / \mathrm{K}$ ratio level $\geq 6.0$ (Fig. 1). Therefore, the spot urine $\mathrm{Na} / \mathrm{K}$ ratio may be beneficial in identifying groups at high risk of developing hypertension. According to a general population-based longitudinal study by Nagahama [3], approximately $8 \%$ of the subjects had $\mathrm{Na} / \mathrm{K}$ ratios $\geq 6.0$ in their spot urine collected between 0900 and $1700 \mathrm{~h}$ at the baseline. Many variables, including fasting time, renal function, and testing season, affect the spot urine $\mathrm{Na} / \mathrm{K}$ value [3], and therefore, the measurement timing is important when employing the spot urine $\mathrm{Na} / \mathrm{K}$ ratio as a risk indicator of hypertension. Biologically and practically, the best way to standardize measurement settings is to use morning spot urine, which was used in the study by Kogure et al. However, it should be noted that elderly patients may underestimate their morning urine $\mathrm{Na} / \mathrm{K}$ ratio levels because of their frequent nocturnal urination [8] and elderly people are more salt-sensitive, which increases their nocturnal sodium excretion during the night $[9,10]$.

Urinary $\mathrm{Na}$ excretion can be reduced by restricting sodium intake. Furthermore, the urinary $\mathrm{Na} / \mathrm{K}$ ratio can also be lowered by increasing the consumption of potassiumrich foods such as leafy greens, fruits, and dairy products 


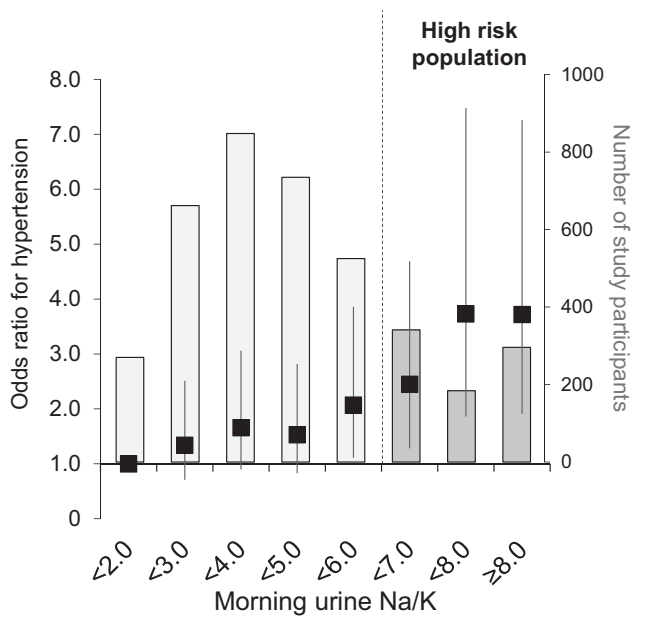

Fig. 1 Associations between a 3-day mean morning urinary sodium-topotassium ratio and home blood pressure levels based on a study by Kogure et al. [7]. The box plot depicts the odds ratio and 95\% confidence interval, while the bar graph depicts the number of study participants

[11]. The correlation between the $\mathrm{Na} / \mathrm{K}$ ratio and $\mathrm{BP}$ level remains consistent regardless of the $\mathrm{Na}$ and $\mathrm{K}$ concentrations [12]. However, increasing potassium intake may be more helpful in lowering BP levels in middle-aged people with preserved renal function, while sodium restriction may be more effective in older people [12].

\section{Compliance with ethical standards}

Conflict of interest The author declares no competing interests.

Publisher's note Springer Nature remains neutral with regard to jurisdictional claims in published maps and institutional affiliations.

\section{References}

1. Lucko AM, Doktorchik C, Woodward M, Cogswell M, Neal B, Rabi D, et al. Percentage of ingested sodium excreted in 24-hour urine collections: a systematic review and meta-analysis. J Clin Hypertens. 2018;20:1220-9. https://doi.org/10.1111/jch.13353
2. Judge C, Narula S, Mente A, Smyth A, Yusuf S, O’Donnell MJ. Measuring sodium intake: research and clinical applications. J Hypertens. 2021;39:2344-52. https://doi.org/10.1097/HJH.0000000 000002951

3. Tabara Y, Takahashi Y, Kumagai K, Setoh K, Kawaguchi T, Takahashi M, et al. Descriptive epidemiology of spot urine sodiumto-potassium ratio clarified close relationship with blood pressure level: the Nagahama study. J Hypertens. 2015;33:2407-13. https:// doi.org/10.1097/HJH.0000000000000734

4. Tanaka T, Okamura T, Miura K, Kadowaki T, Ueshima H, Nakagawa $\mathrm{H}$, et al. A simple method to estimate populational 24-h urinary sodium and potassium excretion using a casual urine specimen. J Hum Hypertens. 2002;16:97-103. https://doi.org/10. 1038/sj.jhh. 1001307

5. Iwahori T, Ueshima H, Ohgami N, Yamashita H, Miyagawa N, Kondo $\mathrm{K}$, et al. Effectiveness of a self-monitoring device for urinary sodium-to-potassium ratio on dietary improvement in freeliving adults: a randomized controlled trial. J Epidemiol. 2018;28:41-7. https://doi.org/10.2188/jea.JE20160144

6. Iwahori T, Ueshima H, Miyagawa N, Ohgami N, Yamashita H, Ohkubo T, et al. Six random specimens of daytime casual urine on different days are sufficient to estimate daily sodium/potassium ratio in comparison to 7-day 24-h urine collections. Hypertens Res. 2014;37:765-71. https://doi.org/10.1038/hr.2014.76

7. Kogure M, Nakamura T, Tsuchiya N, Hirata T, Nochioka K, Narita A, et al. Consideration of the reference value and number of measurements of urinary sodium-to-potassium ratio based on the prevalence of untreated home hypertension: TMM Cohort Study. Hypertens Res. 2022. https://doi.org/10.1038/s41440-021-00843-7

8. Tabara Y, Matsumoto T, Murase K, Setoh K, Kawaguchi T, Nagashima $\mathrm{S}$, et al. Lifestyle habits associated with nocturnal urination frequency: the Nagahama study. Neurourol Urodyn. 2019;38:2359-67. https://doi.org/10.1002/nau.24156

9. Fujii T, Uzu T, Nishimura M, Takeji M, Kuroda S, Nakamura S, et al. Circadian rhythm of natriuresis is disturbed in nondipper type of essential hypertension. Am J Kidney Dis. 1999;33:29-35. https://doi.org/10.1016/s0272-6386(99)70254-4

10. Uzu T, Kazembe FS, Ishikawa K, Nakamura S, Inenaga $T$, Kimura G. High sodium sensitivity implicates nocturnal hypertension in essential hypertension. Hypertension. 1996;28:139-42. https://doi.org/10.1161/01.hyp.28.1.139

11. Yamashita M, Tabara Y, Higo Y, Setoh K, Kawaguchi T, Takahashi $\mathrm{Y}$, et al. Association between socioeconomic factors and urinary sodium-to-potassium ratio: the Nagahama Study. Hypertens Res. 2018;41:973-80. https://doi.org/10.1038/s41440-0180101-X

12. Higo Y, Nagashima S, Tabara Y, Setoh K, Kawaguchi T, Takahashi $\mathrm{Y}$, et al. Association of the spot urine sodium-to-potassium ratio with blood pressure is independent of urinary $\mathrm{Na}$ and $\mathrm{K}$ levels: the Nagahama study. Hypertens Res. 2019;42:1624-30. https://doi.org/10.1038/s41440-019-0276-9 